\title{
Evolving Notions of Knowledge and Learning for Today's Students
}

\author{
Dr. Jerry P. Galloway, Professor \\ Adjunct: University of Texas - Arlington, TX \\ Learning Specialist: Texas Wesleyan University, Ft. Worth, TX
}

\begin{abstract}
This paper addresses current and fundamental issues in the classroom and raises some important issues and perspectives commonly ignored by practicing teachers, their student counterparts and existing literature. This position paper is, essentially, a report of a troubling phenomenon among students, their mindset and motivations, which, if true, has serious implications for learning. Specifically, students' focus on information acquisition over knowledge or understanding and how this skews their motivations in the educational experience. Teachers exacerbate the problem by teaching toward information and skills ignoring the development of knowledge, critical thinking and wisdom. This paper raises issues and suggests further debate and awareness.
\end{abstract}

Keywords: Knowledge, Learning, Understanding, Epistemology, Education, Classroom

\section{Introduction}

Students' motivations and mindset are brought with them when they enter college. Their views of responsibilities, student-teacher roles and their mission are all affected by a lifetime of interaction with parents, previous years of school, relationships and more. By their conduct in the classroom, attention to academics, interaction with instructors and more, they can enable and empower or hinder and undermine the educational process accordingly. What it means to really know something and how learning occurs seems confused at best and perhaps student and faculty perspectives completely inhibit any real progress. Perhaps if the notion of knowledge and learning were clearer and more universally understood, everyone could proceed more efficiently to make progress in today's schools.

\section{Knowledge}

Since there is no agreed upon definition of knowledge (Clarke, 1999), it is equally problematic to define learning as the acquisition of knowledge. As a term, knowledge can be ambiguous and vague and can lend itself to semantic confusion. Students go to college to gain knowledge without knowing what it is they're pursuing and being unable to recognize it when they get it.

Knowledge is unfortunately thought to be the same as information. Students speak of knowing something in terms of whether or not they have the information. Do you know the name of the explorer? Do you know the date of the event? Do you know the distance, the size, the name of this, of that, etc. Thus, knowing something is thought to be the same as having the information. Some definitions of knowledge commonly available unfortunately offer similar accounts (Merriam-Webster, 2007) so it seems to be a common, if not a natural notion. 
Students seem to perceive knowledge in terms of a body of information. This issue seems fundamental to the classroom experience and an integral part of students' personal missions and motivations. While it may be argued that students are neophytes in the experience of formal education and their definitions and perceptions not yet developed or refined, their faculty counterparts ought to know better.

This essay will certainly not resolve the debate over what is and is not knowledge; one of the oldest ideas was promoted by Plato equating knowledge and wisdom. That is, while facts and information might certainly be involved, real knowledge or wisdom demands an awareness, understanding and perspective of principles.

Consistent with this view, George Siemens offers an elegant and simplistic definition of knowledge (Siemens, 2007) and differentiates clearly between knowledge and information. He describes understanding as an emergent property of a network of connections between nodes of information. Not metaphorical at all, these connections and nodes, while certainly abstract, are intended quite literally. Knowledge is defined as the presence of those connections. That is, understanding is a consequence of a sufficient number or threshold of connections.

Siemens does not define the nature of these connections in technical terms using instead anecdotes or real life examples to illustrate the meaning somewhat indirectly. However, connections appear to be a function of associations, interactions, meaningful groupings and, most particularly, relationships. More connections would mean a greater understanding. Meaningfulness resides in the connections not the nodes. That is, establishing connections creates meaning. Creating additional nodes does not.

It is an essential premise in this article that a real problem exists among today's students that they seem to equate knowledge with information - the nodes, rather than the connections between them. This is a critical factor for education, and where teachers are unaware or ignorant of the problem, classroom success is threatened.

\section{Learning Problem}

In the Siemens theory of knowledge, learning might easily be defined as the process of building the connections. While most would agree that education is about acquiring skills and knowledge, the mission is in question to the extent that learning is misunderstood. While skill might utilize or depend on knowledge in part or in whole, skill and knowledge are not the same thing. This author suggests that today's education focuses almost exclusively on skill and too little on the knowledge on which skill depends.

Fitzgerald (2007) accounts for education being about more than knowledge, skills or competence. He describes education as primarily about acquiring the confidence to learn, to ask questions, to understand, to know, to dream and to realize one's aspirations. However, this seems contrary to his acceptance of modern trends of training over education, that job skills and marketable competencies are the primary goal and he does not account for the notion of just becoming smarter or more knowledgeable.

It might be unfair to expect students, as compared to their faculty counterparts, to know some of the finer distinctions of epistemology and what it means to be educated. Nevertheless, students do have ideas and expectations about their mission that can affect what they do and how they do it (S. Galloway, 1999). How students record notes, ask questions and even what they remember can all be affected by their mindset and perspective about what is important and what they believe is expected of them. 
This author suggests a serious problem exists among today's students and faculty regarding confusion and misconception specifically about learning and what that entails. They do not understand their purpose, the nature of the mission they have undertaken, what to expect or how to proceed. Apparently, their faculty counterparts also misunderstand because pedagogy does not seem to address the problem.

Students are interested in information and they believe their job is to acquire information. To put it simply, they view learning as the acquisition of information. They seem to believe that they are to record, memorize and report information. The only challenge they acknowledge, aside from tasking their memorization limits, is to try to distinguish what information is important. For that task, they seem to charge the responsibility to the instructor and classroom teaching. That is, good teaching might be viewed as providing clear distinctions between important and relevant information whereas poor teaching would include a lack of such clarity. This perspective is evident in their course evaluations and summary comments.

To describe this notion further, consider an over simplified example. Students are studying the early discovery of the new world in the late $15^{\text {th }}$ century. They are presented with the fact that Columbus discovered American in 1492. They perceive that the name of the discoverer and the date are the key elements for which they are responsible in the learning task. Indeed, the subsequent exam asks the questions Who discovered America? or When did Columbus discover America? and so forth - perhaps fill-in the blank or multiple choice or true/false. Pedagogy reinforces that approach and that perception of learning. In short, students view education as the process of receiving information, holding on to it for a while, and then reporting it back again to demonstrate that they still have it.

Common or casual language, semantics, expressions all contribute to and reinforce this serious misconception that learning is about information acquisition. Regarding the year of the Columbus discovery, students speak of knowing the year or knowing the name. The question is an inherent part of the classroom experience and the lessons themselves: do you know the year? Etc. This author argues that this is a misnomer and has nothing to do with learning.

\section{Motivations}

Unfortunately, the faculty component of the problem contributes to the failure. Where teachers believe their purpose to be imparting information then little real learning can occur. Where teachers conceive of learning more appropriately, impotence still follows where students are motivated in the traditional approach to acquire information.

Students' expectations in the classroom, brought with them from years of classroom experiences and teacher methodologies, can affect everything. Berghoff (1997) suggests that learning situations are determined by and a consequence of a positional stance, philosophical perspective and expectation. Berghoff's notion is that the stance creates a context of both bias and opportunity wherein experiences yield meaningful significance consistent with that context. One's approach determines the outcome. This suggests that students' expectations and point of view about what is necessary to learn can limit what, how and whether or not they learn at all.

Engaging students in thoughtful discourse can, one might think, help them explore ideas, develop insight and more. However, students' patience and fortitude during a Socraticlike dialogue of question and answer or discussion that explores issues and relationships wanes leaving the student confused and frustrated. If teachers discuss ideas, the activity is filtered by students to find the information. The experience of reflection is supplanted by a quest for facts 
and the teacher seems misdirected from the students' purpose. The whole process again results in frustration for students.

Asking questions of students in order to generate thought or to prompt reflection is again filtered by students who believe they are to recall the factual information that answers the question. Students do not seem to be able to relate to a teacher that is not there to deliver the facts. The classic question of will this be on the test? is entirely designed to differentiate information on which to focus or perhaps information to include in notes and to study later. Of course, the obvious implication is that if the answer to the question about inclusion on a pending exam is no then students need not attend to it at all. And, they do not.

\section{Training vs. Education}

These terms are commonly used interchangeably. For example, in teacher training programs students are said to receive an education. Or, one might say that in teacher education programs, faculties are involved in training teachers. Certainly, training occurs as one learns specific skills and gains new competencies. Today, however, skills seem to be the exclusive focus of educational programs. Students are expected to develop and demonstrate skills and competencies in order to be marketable in society (Fitzgerald, 2007) but to the unfortunate exclusion of any concern for knowledge and wisdom or even just getting smarter.

This problem is probably not uniform across all disciplines. For example, science and mathematics education attends to mental models and resolving misconceptions. Indeed, there are conceptual principles that are common elements of education such as Piaget's conservation of liquid problem where children learn about quantity being independent of the container (Craig, Love, \& Olim, 1973). For adults, science education might include the fundamental conservation of mass-energy, or the $1^{\text {st }}$ Law of Thermodynamics, which simply means that the total mass-energy of the universe does not change (Pidwirny, 2007). Concepts and principles to be understood make up the discipline. Certainly, in doing science (preparing microscope slides, recording data, mixing chemicals, preparing a culture dish, etc.) skills and competencies are involved. But, they are incidental and hardly the focus of the education.

However, in the comparatively newer discipline of instructional technology, training for skills is predominant. That is, mental models, conceptualization and understanding are overlooked in favor of procedural rituals for training new teachers (J. Galloway, 1997). As described above, students' motivations affect how they proceed in learning and this is equally true in this discipline area. Students focus on actions, procedures, formulaic steps for prescribed computing tasks. Students seek recipes that can be replicated without much variance or complication for each computing task.

Computing instructors comply with this expectation by providing step-by-step procedures designed to direct each action in the task. Indeed, so-called quality teaching in educational computing calls for teachers to provide comprehensive procedures for students better teaching means your lists are more sound, complete or accurate. Students expect this and their course evaluations demonstrate such judgments.

The problem of course is simply that this does not constitute learning anything. That is, the student-teacher never actually learns to be a competent user by virtue of the educational experience itself. This misconception about what it takes to successfully master technology as a user or as a teacher precludes experiencing concept-building and other valuable contributory activities. That is, student-teachers resist learning anything and avoid any experiences they will not directly use in the prescribed application how ever limited. Concept-building activities, 
situations that contribute to understanding and resolving misconceptions are avoided in the procedural rituals of training.

The development of intuition, problem-solving and critical thinking abilities consistent with learning and mastery are not commonly recognized as vital for classroom integration of technology or even for becoming competent computer-users. Such elements of education require one to change. Becoming a competent user of technology involves a transformation as one acquires an education - a mastery. Students don't want to change and prefer instead to merely pickup copies of their recipes for later replication and thus their mindset precludes being educated at all.

\section{Recommendations}

First, teachers themselves need to recognize that meaningfulness does not reside in the facts. Teachers should not design assessments to primarily query memorization. Admittedly, asking students about facts can, indirectly, reveal the presence of deeper knowledge and understanding. The point is simply that teachers need to be aware of what they are assessing. It may seem somewhat nebulous but one of the goals of getting an education should be getting smarter (Moursund, 2004). Perhaps this starts with understanding knowledge and learning.

It might be important or at least useful to avoid the use of to know terminology. For students, ask not what you know but what do you understand. For teachers, seek not what your students will know but what your students will understand. Learning is not about information. The acquisition of or having information memorized is a minor concern at best. In today's world, we have information. Information is readily available literally at our finger tips. Whether Internet or television or in print we already have the information. It is not in the having but in the using of information that indicates learning.

Consider: What do students understand? To what and in what way do students relate? What perspective do students have? What problem solving strategies do they employ? What insight does a student have and how do they apply their imagination or intuition? Critical thinking may deal with facts and facts may be necessary but learning addresses how one deals with the information, not the information itself. Siemens' (2007) nodes and emergent properties of a network of connections might be right on target to best illustrate the distinction.

Considering that students bring their motivations and preconceived mindset with them into the classroom, it might be worth addressing change in the earliest possible years. Perhaps students have been conditioned to conduct themselves in a particular way with a particular approach to learning because of pedagogy in the elementary years. It may be that methodologies in earlier levels of schooling precondition students toward particular motivations in learning.

Research is clearly warranted. Research methodologies might also need to be developed to effectively investigate these issues. Research into existing situations might focus on the mindset of students starting college relative to their respective educational backgrounds or targeted discipline areas. An additional resource might be comments in student course evaluations compared to documented teacher styles of those courses.

This author suggests a number of elements that need attention: (a) students' perceptions of responsibility and perceived roles of teachers versus student roles and obligations, (b) relationships between such role perceptions and notions of knowledge and 
learning, and (c) how widespread is the perception outlined in this article that a problem exists. It may be useful to examine recent college graduates or even the public at large. How are facts or mere information differentiated from higher-order thinking in junior and senior high school programs? How is this undermined or enhanced at the college level? Teaching for higher-order thinking skills has long been identified as critical yet lacking in education (Bloom, Englhart, Furst, Hill, \& Krathwohl, 1956). In this new century it is no less important, primary and fundamental in the learning process (Learning Point Associates, 2007).

Teachers' motivations and perspectives, of course, also need to be examined. How do teachers perceive learning and knowledge versus facts and information in their own disciplines? How do instructional methods in the classroom address those distinctions? How do public school teachers differ from college teachers on these issues?

Research into treatments and remedies might be more difficult. One might address how advanced organizers (Anderson, 2004) would improve classroom focus and progress. Assessing something other than information acquisition or discrete skills and competencies might help get at students' decision making abilities, understandings, misconceptions and other higher-order elements of knowledge.

Problem solving requires a problem. Problems are inherently frustrating otherwise there would be no problem. Practice in solving problems can make one better at solving problems and, indeed, make one smarter (Moursund, 2004). So, on a larger scale, perhaps a stronger focus on discovery learning and constructivism (Brooks \& Brooks, 2005) without an exaggerated concern for student frustration might be considered.

While one might even target parenting as an avenue for change, teachers are on the front lines of the battle. As epistemology is a branch of philosophy and fundamental in learning, it might be argued that all teachers, at least in part, must be intellectual philosophers. That is, it is not sufficient that teachers are merely trained or skilled, they must also be thinkers. It may be true that we want college graduates to be skilled with marketable competencies, but we should also find that they are smarter than when they started.

\section{References}

Anderson, B. L. (2004). Advance organizers. A PowerPoint presentation. EdMedia-Technology Solutions for Training \& Marketing. Retrieved August 20, 2007, from: http://www.edmedia.net/courses/281/advorg/index_ao.cfm

Berghoff, B. (1997). Stance and teacher education: Understanding the relational nature of teaching. Paper presented at the National Reading Conference (Scottsdale, AZ, December 6, 1997).

Bloom, B.S., Englhart, M.D., Furst, E.J., Hill, W.H., \& Krathwohl, D.R. (1956) Taxonomy of educational objectives, the classification of educational goals, Handbook I: cognitive domain. New York: Longmans. 
Brooks, J. G., \& Brooks, M. G. (2005). In Search of Understanding: The Case for Constructivist Classrooms, Revised Edition. Online publisher: Diesel eBooks. http://www.dieselebooks.com/

Clarke, R. (1999). Knowledge. Community service pages of the Australian National University. Retrieved August 15, 2007, from: http://www.anu.edu.au/people/Roger.Clarke/SOS/Know.html

Craig, G. J., Love, J. A., \& Olim, E. G. (1973). Perceptual judgments in Piaget's Conservation-ofLiquid problem. Child Development, 44(2), 372-375

Fitzgerald, M. (1998). Beyond the Beginning: The Global Digital Library. Keynote paper: Information, Knowledge and learning: The library in the digital age. Report prepared by The Marc Fresko Consultancy. Retrieved August 14, 2007, from: http://www.cni.org/regconfs/1997/ukoln-content/repor 20.html

Galloway, J. P. (1997). How Teachers Use and Learn To Use Computers. Technology and Teacher Education Annual Journal, 1997. Published by the Association for the Advancement of Computing in Education, Charlottesville, VA.

Galloway, S. A. (1999). Expectations of beginning college students. (Unpublished Masters Thesis, Indiana University Northwest).

Learning Point Associates (2007). 21st Century Skills: Higher-Order Thinking and Sound Reasoning. North Central Regional Educational Laboratory. Retrieved August 23, 2007, from: http://www.ncrel.org/engauge/skills/invent6.htm

Merriam-Webster (2007). Knowledge. Merriam-Webster's Online Dictionary. Retrieved August 15, 2007, from: http://www.m-w.com/dictionary/knowledge

Moursund, D. (2004). Getting Smarter At Solving Problems: Preliminary Edition. Published by the International Society for Technology in Education. Retrieved August 20, 2007, from: http://uoregon.edu/ moursund/Books/GettingSmarter/Getting Smarter.pdf

Pidwirny, M. (2007). Chapter 6: Energy and matter. In M. Pidwirny, Fundamentals of Physical Geography (Ch. 6). University of British Columbia Okanagan. Retrieved August 19, 2007, from: http://www.physicalgeography.net/fundamentals/6e.html

Siemens, G. (2007). A simple definition of knowledge. Knowing and Knowledge Blog. Retrieved August 15, 2007, from:

http://knowingknowledge.com/2007/06/a simple definition of knowled.php 